\title{
Percutaneous Cryoablation for Liver Cancer
}

\author{
Li-Zhi Niu ${ }^{1,2}$, Jia-Liang $\mathrm{Li}^{2}$ and Ke-Cheng $\mathrm{Xu}^{* 1,2}$ \\ ${ }^{1}$ Fuda Cancer Hospital, Jinan University School of Medicine, Tianhe District, Guangzhou, China; ${ }^{2}$ Guangzhou Fuda Cancer \\ Institute, Tianhe District, Guangzhou, China
}

\begin{abstract}
Based on the primary tumor site, liver cancer can be divided into two categories: (1) primary liver cancer and (2) metastatic cancer to the liver from a distant primary site. Guided cryoablation via many imaging methods induces iceball formation and tumor necrosisand is an attractive option for treating unresectable hepatocellular carcinoma (HCC) and metastatic liver cancer. There are several advantages to using cryoablation for the treatment of liver cancer: it can be performed percutaneously, intraoperatively, and laparoscopically; iceball formation can be monitored; it has little impact on nearby large blood vessels; and it induces a cryo-immunological response in situ. Clinically, primary research has shown that percutaneous cryoablation of liver cancer is relatively safe and efficient, and it can be combined with other methods, such as radiation therapy, chemotherapy, and immunology, to control disease. Although research is preliminary, cryosurgery is fast becoming an alternative treatment method for HCC or liver tumors. Here, we review the mechanisms of liver tumor cryoablation, cryoablation program selection, clinical efficiency, and complications following treatment.

(c) 2014 The Second Affiliated Hospital of Chongqing Medical University. Published by XIA \& HE Publishing Ltd. All rights reserved.
\end{abstract}

\section{Introduction}

Liver cancer can be divided into two groups based on the primary tumor site: (1) primary liver cancer (including hepatocellular carcinoma [HCC] and cholangiocarcinoma) and (2) metastatic cancer to the liver from a distant primary site. The most common type of adult primary liver cancer is HCC, which is usually discovered late in the disease course and generally has poor prognosis. ${ }^{1}$ Although surgical resection (SR) is the best option for patients with HCC, only about $20-30 \%$ of patients are eligible for tumor resection at the time of diagnosis. ${ }^{2,3}$ Systemic chemotherapy does not significantly increase survival in patients with advanced

Keywords: Cryosurgery; Hepatocellular carcinoma; Metastatic disease; Efficacy. Abbreviations: AFP, alpha-fetoprotein; CIK, cytokine-induced killer; CT, computed tomography; DCH, dendritic cells; HCC, hepatocellular carcinoma; MRI, magnetic resonance imaging; OS, overall survival; $\mathrm{PC}$, percutaneous cryosurgery; SR, surgical resection; TACE, transarterial chemoembolization; US, ultrasound.

Received: 22 May 2014; Revised: 15 June 2014; Accepted: 27 June 2014

DOI: $10.14218 /$ JCTH.2014.00017.

*Correspondence to: Kecheng $\mathrm{Xu}, \mathrm{No} .2$ of Tangde West Rd, Tianhe District, Guangzhou, China. Tel: +86-020-38993994-8700, Fax: +86-020-389939948700, Email: fudaclab@gmail.com
HCC. ${ }^{4,5}$ Some cancers; such as colorectal, breast, carcinoid and pancreatic cancer, melanoma, and renal cell carcinoma, that can metastasize to the liver are generally associated with poor prognosis as well. Given the lack of treatment options for these patients, new locoregional and systemic therapies are needed. Cryoablation under the guidance of many imaging methods can induce iceball formation and tumor necrosis and is an attractive option for treating unresectable HCC and metastatic liver cancer. Cryoablation has many advantages, including ability to visualize the iceball, 6,7 activation of cryo-immunology in cancer, ${ }^{8}$ lack of severe damage to large blood vessels, ${ }^{9}$ and no causation of severe pain. ${ }^{10}$ With the emergence of argon-helium cryoablation units, percutaneous cryosurgery (PC) is becoming a main treatment method in the field of cancer cryosurgery. The present review describes the mechanisms of liver tumor cryoablation, percutaneous cryoablation program selection, clinical efficiency, and the side effects associated with treatment.

\section{Mechanisms of tissue injury}

Currently, two different argon-based cryoablation units are used in the clinical setting: the CRYO care System (EndoCare, Irvine, CA, USA) and Cryohit (Galil Medical, Yokneam, Israel). When high-pressure argon gas is circulated through the lumen of a cryoprobe, the temperature drops to $-160{ }^{\circ} \mathrm{C}$ and an iceball forms at the tip of the probe. The iceball is thawed when helium gas is circulated through the probe lumen. This freezing and thawing process induces direct and indirect cell damage, causing tumor cell death. When the temperature drops during the freezing process, ice crystals form inside and outside the cell, osmotic pressure increases inside the cell, cell dehydration occurs, and the cell membrane is damaged. ${ }^{11}$ Organelles, such as the mitochondria and endoplasmic reticulum, are irreversibly damaged, eventually leading to cell death. During the thawing process, recrystallization or the mutual confluence of tiny ice crystals leads to the formation of large ice crystals, which induce more damage to the cell. Extracellular water re-enters the cell at this stage, causing the cell to swell, eventually leading to more cell membrane damage. If the temperature of the frozen tissue is not sufficiently decreased, not all tumor cells will be killed despite apoptosis as the main form of cell death. ${ }^{12}$ Since apoptosis does not guarantee the elimination of all target cells, incomplete tumor cell death will likely lead to tumor recurrence.

Cryosurgery is indirectly linked to tumor cell death by promoting arteriovenous injury via the formation of microand small arteriovenous ice crystals that cause vascular endothelial damage, increased vascular wall permeability, 
intravascular fluid extravasation, and interstitial edema. ${ }^{13}$ Platelet aggregation, thrombosis, and eventual occlusion of blood flow also cause tumor tissue ischemia and hypoxia, which induces tumor cell death. The flow of blood in microand small arteries is three times faster than that of intravenous blood, and blood flow influences ice crystal formation. In the first freezing cycle, circulation of microand small arteries of the frozen area recovers 10 20 min after thawing. In the second freezing cycle, micro- and small artery blood flow does not recover, whereas the circulation in large arteries recovers within 24 hours after cryosurgery. ${ }^{14-17}$ After repeated freezing and thawing, cell rupture, cell membrane dissolution, and cell antigen release, the cryo-immunological response is triggered ${ }^{8,18}$ and the anti-tumor immune response that targets additional tumor cells is induced. ${ }^{19}$

\section{Cryoablation program selection}

Several factors influence the effect of freezing, including freezing temperature, freezing time, thawing, and freezing time cycle number. ${ }^{20}$ First, the freezing time controls the size of the iceball, which increases as freezing time increases until a dynamic balance of cold/heat exchange is achieved. As iceball formation can be visualized with ultrasound (US), computed tomography (CT), and magnetic resonance imaging (MRI), ${ }^{20-22}$ it can be monitored accurately to ensure complete ablation. Second, the freezing temperature influences the effect of the cryosurgery. The temperature at the margin of the iceball is $0^{\circ} \mathrm{C}$, a temperature at which tumor cells can survive. Five $\mathrm{mm}$ inside the edge of the iceball, the temperature is approximately $-20{ }^{\circ} \mathrm{C}$ to $-50{ }^{\circ} \mathrm{C}$, and tumor cells can be killed. Therefore, in order to achieve complete ablation of tumor tissue, the edge of the iceball must exceed that of the tumor by $1 \mathrm{~cm} .{ }^{23}$ Third, thawing and cycle times will affect the degree of necrosis, ${ }^{12}$ where a longer thawing time leads to more tissue necrosis. ${ }^{11}$ Whittaker ${ }^{24}$ noted that thawing time will affect iceball formation, where large-scale intracellular ice crystals will form after the second freeze cycle. Repeated freezing cycles will increase the size of the iceball, ${ }^{14,25,26}$ and the degree and area of permanent tissue necrosis caused by the iceball spreads outward as freezing cycles increase, thereby increasing the area of frozen necrosis. ${ }^{27,28}$ Since their freezing times are the same (20 $\mathrm{min})$, the triple-freeze protocol may be a more powerful liver ablation method than the dual-freeze protocol demonstrated in a Tibetan pig model. ${ }^{28}$

As a single probe causes a smaller range of damage, more than two freezing probes are used for tumors exceeding $3 \mathrm{~cm}$ to increase the effective freezing range. ${ }^{29}$ Hinshaw and Lee ${ }^{23}$ reported that if there are no great vessels around the tumor, the best cryoprobe placement is two needles not greater than $2 \mathrm{~cm}$ apart within $1 \mathrm{~cm}$ of the edge of the tumor. If there is a large vessel adjacent to one of the tumor borders, the cryoprobes should be positioned closer to the vessel and more closely apposed, as "heat sink" has a critically important effect on isotherm size and shape. If there are multiple large blood vessels around the tumor, it is best to place the two cryoprobes less than $1 \mathrm{~cm}$ apart, $5 \mathrm{~mm}$ from the edge of the tumor. ${ }^{23}$

Altogether, the efficacy of cryosurgery is affected by argon flow to specific probes, the cryoablation program, and multiple probe selection. For liver cryosurgery, different cryoablation programs are carried out to ablate different lesions or lesions in different locations.

\section{Clinical research (summarized in Table 1)}

In this decade, $\mathrm{PC}$ is the main therapeutic intervention for the treatment of unresectable HCC. In 2003, Xu et al. ${ }^{44}$ reported the use of PC in 105 masses from 65 patients with HCC. Among 41 patients who were followed for more than 1 year; $32(78 \%)$ were alive despite tumor recurrence, seven patients $(10.8 \%)$ died due to disease recurrence, and three patients ( $5 \%$ ) died of non-cancer-related diseases (Fig. 1). In a study of four patients with small HCC who underwent one PC with multiple 17-G cryoprobes, it was determined that this percutaneous technique, and not the laparotomic approach, should be applied for unresectable HCC. ${ }^{30}$ In 300 cases of $\mathrm{HCC}$, the therapeutic effect, safety, and complications of PC were evaluated, and the mean survival (months) of early-, intermediate-, and advanced-stage patients was $38.7 \pm 3.8$,

Table 1. Survival rates of patients after cryosurgery of hepatic tumors

\begin{tabular}{|c|c|c|c|c|c|c|c|c|}
\hline & Tumor type & Therapy type & Patients & $\begin{array}{l}1 \text { year } \\
\text { survival rate } \\
(\%)\end{array}$ & $\begin{array}{l}2 \text { year } \\
\text { survival } \\
\text { rate }(\%)\end{array}$ & $\begin{array}{l}3 \text { year } \\
\text { survival } \\
\text { rate }(\%)\end{array}$ & $\begin{array}{l}4 \text { year } \\
\text { survival } \\
\text { rate }(\%)\end{array}$ & $\begin{array}{l}5 \text { year } \\
\text { survival } \\
\text { rate }(\%)\end{array}$ \\
\hline Zhou et al. ${ }^{32-33}$ & $\mathrm{HCC}$ & CRY & 48 & 81.3 & 62.1 & 47.6 & 44.4 & - \\
\hline Chen et al. ${ }^{20}$ & $\mathrm{HCC}$ & CRY & - & 81.4 & - & 60.3 & - & - \\
\hline Li et al. ${ }^{36}$ & SHCC & CRY & - & 100.0 & - & 77.6 & 70.7 & - \\
\hline Xu et al. ${ }^{37}$ & $\begin{array}{l}\text { Colorectal liver } \\
\text { metastases }\end{array}$ & CRY & 326 & 78.0 & 62.0 & 41.0 & 34.0 & 23.0 \\
\hline Qian et al. 38 & $\begin{array}{l}\text { Metastatic liver } \\
\text { malignancy }\end{array}$ & CRY & 22 & 81.8 & 22.7 & - & - & - \\
\hline \multirow[t]{2}{*}{ Chen et al. ${ }^{39}$} & Secondary Liver cancer & CRY & - & 80.2 & - & - & - & - \\
\hline & Recurrent liver cancer & CRY & - & 46.2 & - & - & - & - \\
\hline Han et al. ${ }^{40}$ & $\mathrm{HCC}$ & CRY & 116 & 85.7 & 64.3 & 32.1 & - & - \\
\hline \multirow[t]{2}{*}{ Xu et al. ${ }^{42}$} & $\mathrm{HCC}$ & CRY & 420 & 73.0 & 54.0 & - & 49.0 & 39.0 \\
\hline & $\mathrm{HCC}$ & $\mathrm{TACE}+\mathrm{CRY}$ & - & 71.0 & 61.0 & - & 29.0 & 23.0 \\
\hline
\end{tabular}

Note: SHCC, small HCC; CRY, cryotherapy 

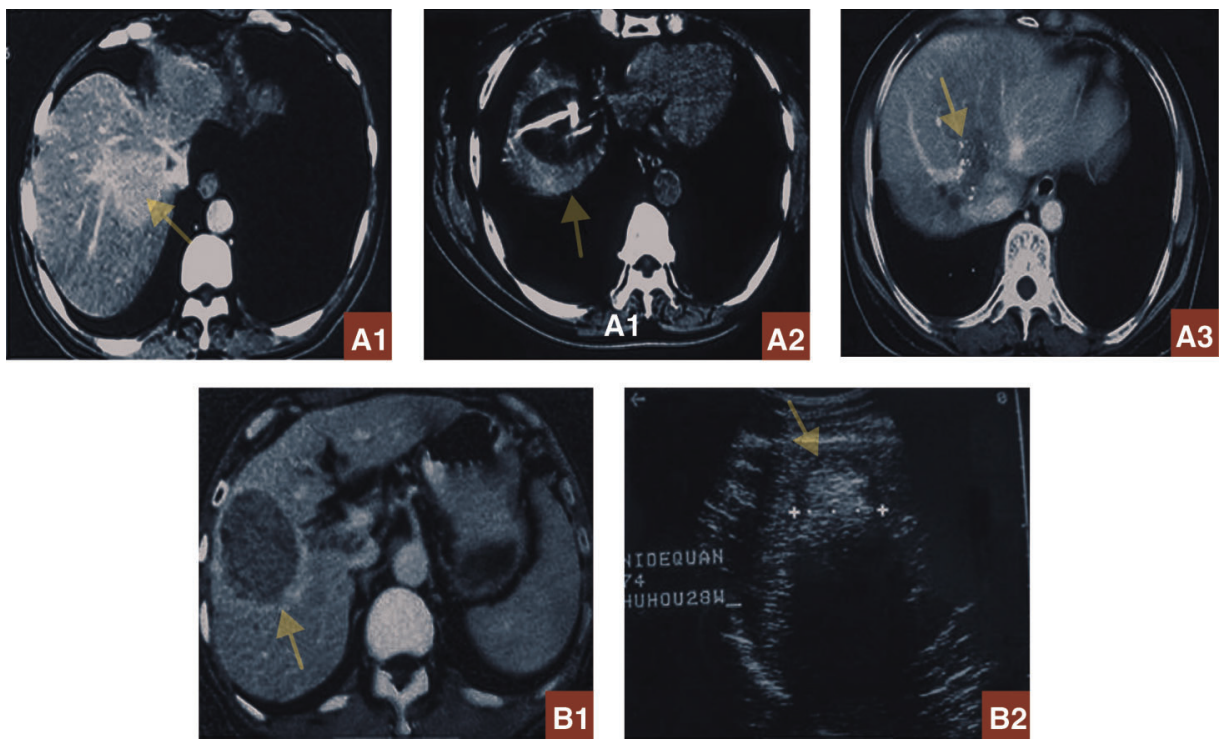

Fig. 1. CT images of two patients (A and B) with HCC who underwent PC. (A1) Space-occupying lesion in the upper right part of the liver. (A2) Cryoprobe placement and resultant iceball formation. (A3) No lesion five years after treatment. (B1) Space-occupying lesion measuring $73 \times 62 \mathrm{~mm}$ before treatment. (B2) Ultrasonography showing shrinkage of the tumor to $42 \times 40 \mathrm{~mm}$. Arrows indicate the tumor site.

$26.5 \pm 4.2$, and $16.9 \pm 1.4$, respectively. ${ }^{31}$ There were serious complications in 17 patients $(6 \%)$, including six with cold shock ( $2 \%)$, five with bleeding due to tumor rupture $(2 \%)$, four with bleeding from stress gastric ulcer $(1 \%)$, and two with liver failure $(1 \%)$. In another study, the clinical effectiveness of percutaneous cryosurgical ablation for treating 48 patients with early-stage HCC was evaluated, and it was found that the $1,2,3$, and 4 year survival rates were $81 \%, 62 \%, 48 \%$, and $44 \%$, respectively. ${ }^{32,33}$ In a series of 124 unresectable HCC cases, serum alpha-fetoprotein (AFP) levels were reduced in 76 patients (83\%), and 205 of the 222 tumors $(92 \%)$ diminished or were unchanged after cryoablation. The median survival time was $31.3,17.4$, and 6.8 months in the early-, intermediate-, and advanced-stage groups, respectively. In eight patients with primary or secondary small HCC $(\leqslant 5 \mathrm{~cm})$ after PC, six patients became AFP negative with a coagulation necrosis rate of $63 \%$, and the 6 month and 1 year local recurrence-free survival rates were $100 \%$ and $88 \%$, respectively. ${ }^{34}$ Zhang investigated 227 patients with different stages of HCC treated with PC and found that advanced HCC was most sensitive to cryosurgery and that survival was significantly prolonged. ${ }^{35}$ Using PC to treat patients with unresectable HCC, Chen et al. ${ }^{20}$ found that the 1 and 3 year overall survival (OS) rates were $81 \%$, and $60 \%$, respectively, while the 1 and 3 year disease-free survival rates were $68 \%$ and $21 \%$, respectively. The 1 and 3 year OS rates of patients with recurrent $\mathrm{HCC}$ were $70 \%$ and $29 \%$, respectively, while the 1 and 3 year disease-free survival rates were $54 \%$ and $8 \%$, respectively. When the therapeutic effect of PC and SR of small HCC were compared, it was found that the respective 1,3 , and 5 year OS rates of the PC and SR groups were $100 \%, 75 \%$, and $67 \%$, and $100 \%, 78 \%$, and $71 \%{ }^{36}$ The respective 1,3 , and 5 year recurrence-free survival rates of the PC and SR group were $83 \%, 46 \%$, and $29 \%$, and $84 \%, 48 \%$, and $33 \%$. These results suggested that $\mathrm{PC}$ is as effective as SR for treating solitary small HCC even though it is less invasive, requires a shorter hospitalization time, and less expensive than SR. Overall, these data demonstrate that PC is a viable treatment option for HCC.

Similar to its use in primary liver cancer, cryosurgery also is advantageous for the treatment of metastatic liver cancer. In 326 patients with non-resectable hepatic colorectal metastases, 526 procedures of cryosurgery under US or CT guidance were performed. ${ }^{37}$ Three months after cryosurgery, the elevated carcinoembryonic antigen levels in $78 \%$ of patients were restored to normal levels. Postoperative CT scan of the cryotreated lesions showed complete response in $15 \%$ of patients, partial response in $41 \%$ of patients, and stable disease in $24 \%$ of patients. The $1,2,3,4$, and 5 year OS rates after the treatment were $78 \%, 62 \%, 41 \%, 34 \%$, and $23 \%$, respectively (Fig. 2). In 2005, Qian and colleagues $^{38}$ reported survival rates of 22 patients with histologically or clinically confirmed metastatic liver malignancy treated with PC. The 12, 18, and 24 month survival rates were $82 \%, 64 \%$, and $23 \%$, respectively. Chen et al. ${ }^{39}$ reported that the 1 year survival rates of secondary and recurrent liver cancer patients treated with cryosurgery were $80 \%$ and $46 \%$, respectively. In another study, 116 patients with unresectable HCC were divided into three groups: (A) interventional therapy, (B) 3-dimensional conformal radiotherapy, and (C) cryoablation therapy. The respective 1,2 , and 3 year survival rates in the $A, B$, and $C$ groups were $15 \%$, $64 \%$, and $86 \% ; 11 \%, 32 \%$, and $64 \%$; and $0 \%, 0 \%$, and $32 \%$. Taken together, these data suggest that PC is an acceptable new locoregional therapy for metastatic liver cancer.

In order to optimize treatment strategies for liver cancer, cryoablation is often combined with other therapies, such as transarterial chemoembolization (TACE). Between July 2001 and June 2002, Qian et al. ${ }^{41}$ assessed the indications, efficacy, and clinical significance of PC following TACE in 34 patients with histologically or clinically confirmed primary or metastatic carcinoma. During the 3-15 month follow-up 
Niu L.Z. et al: Cryoablation for liver cancer
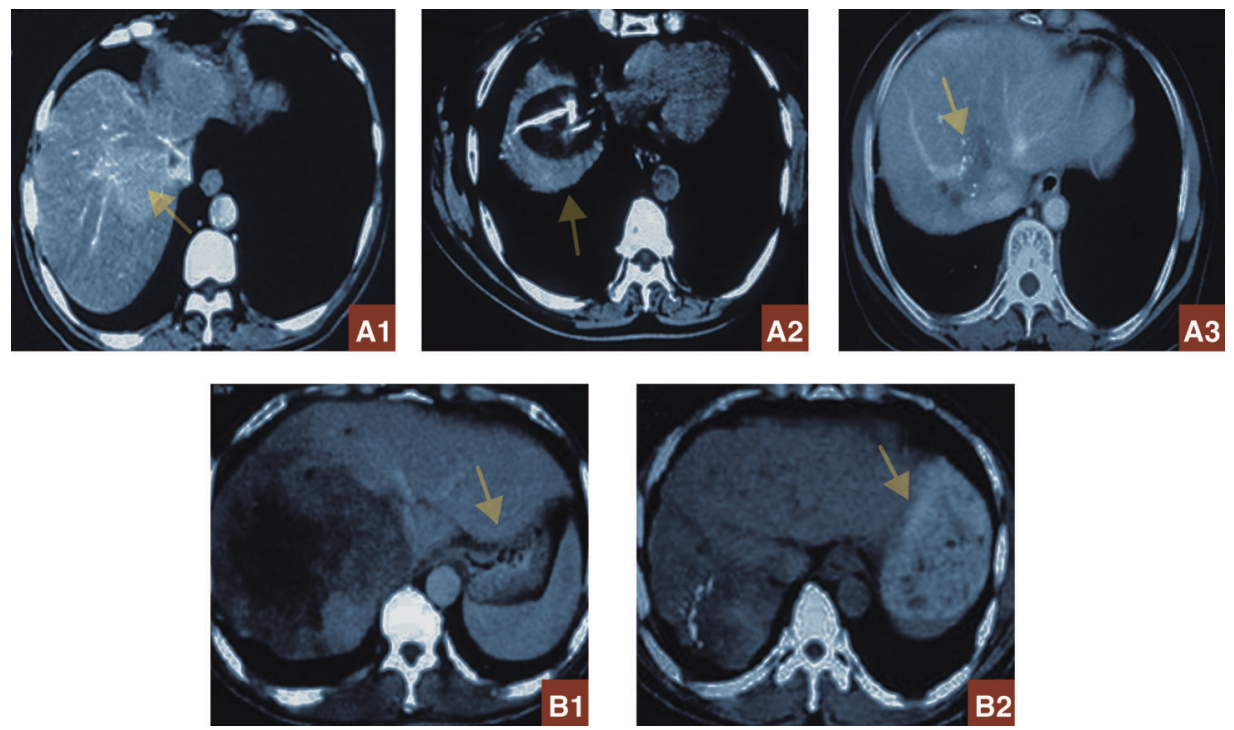

Fig. 2. Liver imaging in two patients (A and B) with hepatic colorectal metastases. Complete ablation of histologically proven tumor was achieved after PC. (A1) MRI before cryosurgery. (A2) MRI during CT-guided PC. (A3) MRI at 12 months after cryosurgery. In the second patient, the massive lesion regressed completely in comparison to its size before cryosurgery (B1). (B2) Eight months after cryosurgery and TACE. Arrows indicate the tumor site.

period, $41 \%$ of patients were classified as clinically cured or effectively treated because their serum tumor markers were normal, or CT and MRI images revealed that the lesion had become completely necrotic. In a study on the use of sequential TACE and PC for treatment of unresectable HCC, the 1 and 2 year survival rates in the sequential group (71\% and $61 \%$, respectively) were similar to that of the cryo-alone group (73\% and 54\%, respectively). The 4 and 5 year survival rates of the sequential group were $49 \%$ and $39 \%$, respectively, which were higher than that of the cryo-alone group ( $29 \%$ and $23 \%$, respectively). While 18 patients with large $\mathrm{HCC}(>5 \mathrm{~cm}$ diameter) survived for more than 5 years after sequential TACE and cryosurgery, no patient in this category survived more than five years with cryosurgery alone. The authors suggested that pre-cryosurgical TACE may increase the efficacy of cryoablation and decrease its adverse effects, especially bleeding. Therefore, sequential TACE and cryosurgery may be a better therapeutic option for unresectable HCC, especially large HCC. In another study comparing PC followed by TACE with TACE alone for advanced liver cancer, the rate of effectiveness of the combined group was $100 \%$ and only $47 \%$ in the TACE alone group. ${ }^{43}$ When determining the effect of order for combination cryosurgery and TACE in 40 patients with advanced primary hepatic carcinoma, about half of patients exhibited complete tumor necrosis, and there was no significant difference between the TACE/sequential cryosurgery and cryosurgery/sequential TACE groups. ${ }^{44}$ However, progression-free survival in the TACE/sequential cryosurgery group was significantly longer than that of the cryosurgery/sequential TACE group. Regarding combining cryoablation with gemcitabine + oxaliplatin for the treatment of advanced liver cancer, combination therapy was found to be more efficacious, reliable and safe than monotherapy. ${ }^{45}$

In a study with combination hepatic $\mathrm{PC}$ and percutaneous ethanol injection for unresectable HCC, 33 patients (51\%) were tumor-free and 22 patients (34\%) were alive with tumor recurrence during a mean follow-up period of 14 months (range 5-21 months). As cryoablation of tumors in multiple organs (i.e., liver, lung, kidney, breast, pancreas, and prostate ${ }^{47}$ ) has been demonstrated to be safe and effective, comprehensive cryoablation (simultaneous cryoablation of intrahepatic and extrahepatic tumors) significantly improves the survival of metastatic hepatocellular cancer, and timely or multiple treatments may both contribute more towards the therapeutic effects than delayed or single treatment. ${ }^{48}$ Although cryosurgery can induce a cryo-immunological response, 8,19 the anti-tumor immune response is insufficiently strong to prolong patient life. At the same time, immunotherapy mediated by autologous dendritic cells (DCs) is a promising treatment option for the long-lasting control of unresectable HCC. ${ }^{49-51}$ Increased knowledge of vaccination using DCs co-cultured with cytokine-induced killer (CIK) cells has led to the formulation of better strategies in the clinical treatment of hepatic cancer. ${ }^{52}$ Combining these approaches, Niu et al. ${ }^{53}$ evaluated whether combination PC and DC-CIK immunotherapy can improve the therapeutic effect of cryosurgery for patients with metastatic hepatocellular cancer. To stimulate DC recognition of tumor antigens in vivo, harvested DC-CIKs were transfused into patients one week after cryosurgery. The median OS of the cryo-DC-CIK immunotherapy group (32 months) was higher than that of the cryotherapy group (18 months) and the untreated group ( 3 months), and multiple cryo-immunotherapy was associated with better prognosis than single cryo-immunotherapy. ${ }^{53}$ Perhaps cryosurgery induces continuous antigen release in vivo, and the adoptive transfer of CIK cells along with DCs can present tumor antigens and destroy tumor cells in the body. Another advantage of cryosurgery is the destruction of the organ-like structural environment of a tumor, which is considered hostile toward immune cells. Altogether, it appears that PC and DC-CIK immunotherapy may be an alternative therapeutic option for improving survival in metastatic hepatocellular cancer. 
Niu L.Z. et al: Cryoablation for liver cancer

Table 2. Serious complications after hepatic cryoablation

\begin{tabular}{|c|c|c|c|}
\hline \multirow[b]{2}{*}{ Tumor type } & \multirow{2}{*}{$\begin{array}{l}\text { Yang et al. }{ }^{56} \\
\mathrm{HCC}\end{array}$} & \multirow{2}{*}{$\begin{array}{l}\text { Xu et al. }{ }^{37} \\
\text { Colorectal liver } \\
\text { metastases }\end{array}$} & \multirow{2}{*}{$\begin{array}{l}\text { Mu et al. }{ }^{48} \\
\text { Metastatic } \\
\text { hepatocellular cancer }\end{array}$} \\
\hline & & & \\
\hline Number of patients & 300 & 326 & 33 \\
\hline Cryoshock syndrome & $6(2.0 \%)$ & $1(0.3 \%)$ & - \\
\hline Bleeding & $5(1.6 \%)$ & $5(1.5 \%)$ & $6(18.0 \%)$ \\
\hline Liver abscess & $2(0.6 \%)$ & $3(0.9 \%)$ & $2(6.0 \%)$ \\
\hline Liver failure & $2(0.6 \%)$ & $1(0.3 \%)$ & - \\
\hline Liver dysfunction & $7(2.3 \%)$ & - & - \\
\hline Biliary fistulas & - & $3(0.9 \%)$ & - \\
\hline Intestinal fistulas & $1(0.3 \%)$ & - & - \\
\hline Renal insufficiency & - & $5(1.5 \%)$ & - \\
\hline Acute myocardial infarction and severe arrhythmia & $6(2 \%)$ & $2(0.6 \%)$ & - \\
\hline Pain & - & $103(31.6 \%)$ & $13(76.0 \%)$ \\
\hline Fever & $6(2 \%)$ & $108(33.1 \%)$ & - \\
\hline Increased liver enzymes & - & $124(38.0 \%)$ & - \\
\hline Thrombocytopenia & - & $58(17.8 \%)$ & $7(21.0 \%)$ \\
\hline Pleural effusion & - & $20(6.1 \%)$ & $2(6.0 \%)$ \\
\hline Liver capsular cracking & $1(0.3 \%)$ & - & $1(3.0 \%)$ \\
\hline Gastric mucosal lesion-induced hemorrhage & $4(1.3 \%)$ & - & - \\
\hline
\end{tabular}

\section{Adverse effects (summarized in Table 2)}

Adverse effects of varying degrees of severity during and after hepatic cryoablation have been documented. In liquid nitrogen ablation, the frequency of adverse effects may be as high as $40 \%$ and include liver parenchyma fracture, cryoshock, acute myocardial infarction, biliary fistula, hemorrhage, cold-induced lesions in nearby structures, thrombocytopenia, and coagulopathy. ${ }^{54,55}$ Hepatic cryoablationrelated mortality is $1.5 \%,{ }^{56}$ almost the same as that for liver resection. There are relatively fewer and milder adverse effects associated with percutaneous cryoablation than liquid nitrogen cryoablation. Serious complications, including hepatic failure, rupture, and cold shock, are occasionally observed after the procedure. ${ }^{37,48}$

In one study of $300 \mathrm{HCC}$ patients who underwent USguided PC, 6\% developed serious complications, including cryoshock syndrome in six patients, hepatic bleeding in five, stress-induced gastric bleeding in four, liver abscess in one, intestinal fistulas in one, and death due to liver failure in two. ${ }^{57}$ Cold shock, a rare and serious complication of hepatic cryoablation, has garnered much attention from clinical researchers. The clinical features of cold shock include varying degrees of renal failure, disseminated intravascular coagulation, and adult respiratory distress syndrome. Its occurrence is proportional to the size of the frozen tissue, and often happens when the diameter of the area frozen exceeds $6 \mathrm{~cm} .58$

Alternatively, freezing time rather than frozen area may be much more important for the occurrence of cold shock. ${ }^{59}$ Another potentially serious complication that can lead to death is an argon-helium gas embolism. ${ }^{60}$ Minor complications due to PC are chills, fever, hepatic region pain, and elevated serum enzymes, which can be efficiently controlled with symptomatic treatment. 37,48 Coagulopathy, another complication of hepatic cryoablation, occurs due to the trapping and destruction of local platelets within the margin of the cryolesion. ${ }^{61-63}$ The development of thrombocytopenia is associated with increased length of stay and mortality. ${ }^{64-66}$ Although thrombocytopenia is considered relative to the volume of frozen tissue, ${ }^{63,67}$ the number of freeze-thaw cycles, and the number of cryoprobes, ${ }^{68}$ Shi et al. ${ }^{69}$ showed that the diameter of the ablation does not limit the tendency of platelets to change. Slight coagulopathy (platelet count $\left.[70-100] \times 10^{9} / \mathrm{L}\right)$ can recover naturally within a week, and recombinant human interleukin-11 can assist recovery from severe coagulopathy (platelet count $<70 \times 10^{9} / \mathrm{L}$ ). ${ }^{69}$ At the same time, PC of hepatic tumors may cause short-term pain in some patients, which disappears within 15 days, and the effect of alleviating cancer pain is sustained for $>8$ weeks without severe side effects. ${ }^{70}$ Tumor seeding can be detected in $0.8 \%$ of patients at $1-24$ months (median, 6 months) after cryoablation. ${ }^{71,72}$

Therefore, monitoring liver function and detecting blood coagulation and renal function are very important before or after hepatic cryoablation. Cryosurgery program selection, accuracy of preoperative localization, and the frozen range all can affect the occurrence of complications. To avoid serious complications, all patients should be given diuretics and mannitol, and their urine alkalized to prevent myoglobinuria and renal injury.

\section{Conclusions}

Experimental and clinical applications have shown that hepatic cryosurgery is safe and efficacious. Iceball formation can be monitored visually, and cryoablation has little impact on nearby large blood vessels. Cryosurgery can be performed on its own or in combination with other methods, such as radiation therapy, chemotherapy, immunology, or surgery, to 
control disease. In the future, the safety and efficacy of hepatic cryosurgery in specific areas of the liver lobe close to the diaphragm and gall bladder should be examined. Presently, there are several ablation techniques available for hepatic cancer, such as radiofrequency, microwave, irreversible electroporation, and cryosurgery. The ability to compare these techniques and to know which patients are the best candidates for each technique is of great importance. Simultaneously, optimizing therapeutic conditions to enhance the efficacy and safety of combination cryosurgery with other therapies requires further investigation.

\section{Conflict of interest}

None

\section{Author contributions}

Performing all the cryosurgeries (LZN), Writing the paper (JLL), Conducting and reviewing the article (KCX).

\section{References}

[1] Jemal A, Bray F, Center MM, Ferlay J, Ward E, Forman D. Global cancer statistics. CA Cancer J Clin 2011;61:69-90. doi: 10.3322/caac.20107.

[2] Hodgson HJ. Primary hepatocellular carcinoma. Br] Hosp Med 1983;29:240, 246, 250 passim.

[3] Dusheiko GM, Hobbs KE, Dick R, Burroughs AK. Treatment of small hepatocellular carcinomas. Lancet 1992;340:285-288. doi: 10.1016/ 0140-6736(92)92367-0.

[4] Burroughs A, Hochhauser D, Meyer T. Systemic treatment and liver transplantation for hepatocellular carcinoma: two ends of the therapeutic spectrum. Lancet Oncol 2004;5:409-418. doi: 10.1016/S14702045(04)01508-6.

[5] Llovet JM, Ricci S, Mazzaferro V, Hilgard P, Gane E, Blanc JF, et al. Sorafenib in advanced hepatocellular carcinoma. N Engl J Med 2008;359:378-390. doi: 10.1056/NEJMoa0708857.

[6] Littrup PJ, Ahmed A, Aoun HD, Noujaim DL, Harb T, Nakat S, et al. CT-guided percutaneous cryotherapy of renal masses. J Vasc Interv Radiol 2007;18: 383-392. doi: 10.1016/j.jvir.2006.12.007.

[7] Littrup PJ, Freeman-Gibb L, Andea A, White M, Amerikia KC, Bouwman D, et al. Cryotherapy for breast fibroadenomas. Radiology 2005;234:63-72. doi: $10.1148 /$ radiol. 2341030931.

[8] Sabel MS. Cryo-immunology: a review of the literature and proposed mechanisms for stimulatory versus suppressive immune responses. Cryobiology 2009;58:1-11. doi: 10.1016/j.cryobiol.2008.10.126.

[9] Ladd AP, Rescorla FJ, Baust JG, Callahan M, Davis M, Grosfeld JL. Cryosurgical effects on growing vessels. Am Surg 1999;65:677-682.

[10] Arciero CA, Sigurdson ER. Liver-directed therapies for patients with primary liver cancer and hepatic metastases. Curr Treat Options Oncol 2006;7:399409. doi: 10.1007/s11864-006-0008-7.

[11] Gage AA, Baust J. Mechanisms of tissue injury in cryosurgery. Cryobiology 1998;37:171-186. doi: 10.1006/cryo.1998.2115.

[12] Hanai A, Yang WL, Ravikumar TS. Induction of apoptosis in human colon carcinoma cells HT29 by sublethal cryo-injury: mediation by cytochrome c release. Int J Cancer 2001;93:526-533. doi: 10.1002/ijc.1359.

[13] Mazur P. Freezing of living cells: mechanisms and implications. Am J Physio 1984;247: C125-142.

[14] Hoffmann NE, Bischof JC. The cryobiology of cryosurgical injury. Urology 2002;60:40-49. doi: 10.1016/S0090-4295(02)01683-7.

[15] Irimia D, Karlsson JO. Kinetics of intracellular ice formation in onedimensional arrays of interacting biological cells. Biophys J 2005;88:647660. doi: 10.1529/biophysj.104.048355.

[16] Eggstein S, Neeff H, Szarzynski M, Jungraithmayr W, Haberstroh J, Kirste G, et al. Hepatic cryotherapy involving the vena cava. Experimental study in a pig liver model. Eur Surg Res 2003;35:67-74. doi: 10.1159/000069398.

[17] Gage AA, Fazekas G, Riley EE Jr. Freezing injury to large blood vessels in dogs. With comments on the effect of experimental freezing of bile ducts. Surgery 1967;61:748-754.

[18] Hoffmann NE, Coad JE, Huot CS, Swanlund DJ, Bischof JC. Investigation of the mechanism and the effect of cryoimmunology in the Copenhagen rat. Cryobiology 2001;42:59-68. doi: 10.1006/cryo.2001.2305.
[19] Rovere-Querini P, Manfredi AA. Tumor destruction and in situ delivery of antigen presenting cells promote anti-neoplastic immune responses: implications for the immunotherapy of pancreatic cancer. JOP 2004;5:308-314.

[20] Chen HW, Lai EC, Zhen ZJ, Cui WZ, Liao S, Lau WY. Ultrasound-guided percutaneous cryotherapy of hepatocellular carcinoma. Int J Surg 2011;9: 188-191. doi: 10.1016/j.ijsu.2010.11.008

[21] Lee FT Jr, Chosy SG, Littrup PJ, Warner TF, Kuhlman JE, Mahvi DM. CTmonitored percutaneous cryoablation in a pig liver model: pilot study. Radiology 1999;211:687-692. doi: 10.1148/radiology.211.3.r99jn29687.

[22] Silverman SG, Sun MR, Tuncali K, Morrison PR, van Sonnenberg E, Shankar S, et al. Three-dimensional assessment of MRI-guided percutaneous cryotherapy of liver metastases. AJR Am J Roentgenol 2004;183:707-712. doi: 10.2214/ajr.183.3.1830707

[23] Hinshaw JL, Lee FT Jr. Cryoablation for liver cancer. Tech Vasc Interv Radiol 2007; 10:47-57. doi: 10.1053/j.tvir.2007.08.005

[24] Whittaker DK. Repeat freeze cycles in cryosurgery of oral tissues. Br Dent ] 1975;139:459-465. doi: 10.1038/sj.bdj.4803667.

[25] Mala T, Edwin B, Tillung T, Kristian Hol P, Soreide O, Gladhaug I. Percutaneous cryoablation of colorectal liver metastases: potentiated by two consecutive freeze-thaw cycles. Cryobiology 2003;46:99-102. doi: 10.1016/S00112240(02)00163-3.

[26] Rubinsky B, Lee CY, Bastacky J, Onik G. The process of freezing and the mechanism of damage during hepatic cryosurgery. Cryobiology 1990;27: 85-97. doi: 10.1016/0011-2240(90)90055-9.

[27] Dilley AV, Dy DY, Warlters A, Copeland S, Gillies AE, Morris RW, et al. Laboratory and animal model evaluation of the Cryotech LCS 2000 in hepatic cryotherapy. Cryobiology 1993;30:74-85. doi: 10.1006/cryo.1993.1007.

[28] Li J, Chen J, Zhou L, Zeng J, Yao F, Wu B, et al. Comparison of dual- and triplefreeze protocols for hepatic cryoablation in a Tibet pig model. Cryobiology 2012;65:68-71. doi: 10.1016/j.cryobiol.2012.04.004.

[29] Bilchik AJ, Wood TF, Allegra D, Tsioulias GJ, Chung M, Rose DM, et al. Cryosurgical ablation and radiofrequency ablation for unresectable hepatic malignant neoplasms: a proposed algorithm. Arch Surg 2000;135:657-662; discussion 662-654. doi: 10.1001/archsurg.135.6.657

[30] Orlacchio A, Bazzocchi G, Pastorelli D, Bolacchi F, Angelico M, Almerighi C, et al. Percutaneous cryoablation of small hepatocellular carcinoma with US guidance and CT monitoring: initial experience. Cardiovasc Intervent Radiol 2008;31:587-594. doi: 10.1007/s00270-008-9293-9.

[31] Wang CP, Lu YY, Wang XZ. Percutaneous argon-helium cryoablation for primary hepatocellular carcinoma: report of 300 cases. Jie Fang Jun Yi Xue Za Zhi 2008;33:1413-1417

[32] Zhou H, Niu L, Zhou L, Mu F, Zhang C, Liang B, et al. Cryosurgery combined with Iodine-125 seed implantation in the treatment of unresectable lung cancer. Zhongguo Fei Ai Za Zhi 2008;11:780-783.

[33] Zhou L, Yang YP, Feng YY. Efficacy of argon-helium cryosurgical ablation on primary hepatocellular carcinoma: a pilot clinical study. Ai Zheng 2009;28: 45-48.

[34] Qian G], Wang N, Wu SP. Percutaneous cryoablation for liver cancer located in the second hepatic. Gan Dan Wai Ke Za Zhi 2008;16:334-336.

[35] Zhang MN, Lu YY, Wang XZ. Clinical study of argon-helium cryosurgical ablation in the treatment for hepatocellular carcinoma. Zhongguo Zhong Liu 2009;18:329-331.

[36] Li Z, Zhang C, Lou C, Yan F, Mao Y, Hong X, et al. Comparison of percutaneous cryosurgery and surgical resection for the treatment of small hepatocellular carcinoma. Oncol Lett 2013;6:239-245. doi: 10.3892/ol.2013.1314.

[37] Chen HW, Cui WZ, Zhang HX. Ultrasound-guided minimally invasive targeting argon-helium cryoablation in the treatment of hepatic carcinoma. Zhongguo Shi Yong Wai Ke Za Zhi 2008;28:637-646.

[38] Han L, Wen XP, Wang WL. Clinical study on interventional therapy, threedimensional conformal radiotherapy and targeted argon-helium cryoablation to primary hepatocellular carcinoma. Guizhou Yi Yao 2010;34:687-690.

[39] Qian G], Chen H, Wu MC. Percutaneous cryoablation after chemoembolization of liver carcinoma: report of 34 cases. Hepatobiliary Pancreat Dis Int 2003; $2: 520-524$

[40] Xu KC, Niu LZ, Zhou Q, Hu YZ, Guo DH, Liu ZP, et al. Sequential use of transarterial chemoembolization and percutaneous cryosurgery for hepatocellular carcinoma. World J Gastroenterol 2009;15:3664-3669.

[41] Shen XW, Feng J, Sun XG. Argon-helium cryosurgery combined with transcatheter arterial chemoembolization for treatment of liver metastatic tumors: an analysis of therapeutic results. Jie Ru Fang She Xue Za Zhi 2010; 19:35-37.

[42] Cao Y, Zhao D, Wang Y. Clinical observation of cryosrugery with TACE by different order on the survival of advanced primary hepatic carcinoma. Chin J Mod Drug Appl 2013;7:9-11.

[43] Bai GD, Lian ZP, Huang DP. Cryoablation combined with chemotherapy in the treatment of advanced primary liver cancer. Dang Dai Yi Xue 2010;16:293295.

[44] Xu KC, Niu LZ, He WB, Guo ZQ, Hu YZ, Zuo JS. Percutaneous cryoablation in combination with ethanol injection for unresectable hepatocellular carcinoma. World J Gastroenterol 2003;9:2686-2689. 
[45] Gage AA, Baust JM, Baust JG. Experimental cryosurgery investigations in vivo. Cryobiology 2009;59:229-243. doi: 10.1016/j.cryobiol.2009.10.001.

[46] Mu F, Niu L, Li H, Liao M, Li L, Liu C, et al. Percutaneous comprehensive cryoablation for metastatic hepatocellular cancer. Cryobiology 2013;66:7680. doi: 10.1016/j.cryobiol.2012.11.008.

[47] Palmer DH, Midgley RS, Mirza N, Torr EE, Ahmed F, Steele JC, et al. A phase II study of adoptive immunotherapy using dendritic cells pulsed with tumor lysate in patients with hepatocellular carcinoma. Hepatology 2009;49:124132. doi: 10.1002/hep.22626.

[48] Lee WC, Wang HC, Hung CF, Huang PF, Lia CR, Chen MF. Vaccination of advanced hepatocellular carcinoma patients with tumor lysate-pulsed dendritic cells: a clinical trial. J Immunother 2005;28:496-504. doi: 10.1097/01.cji.0000171291.72039.e2.

[49] Iwashita Y, Tahara K, Goto S, Sasaki A, Kai S, Seike M, et al. A phase I study of autologous dendritic cell-based immunotherapy for patients with unresectable primary liver cancer. Cancer Immunol Immunother 2003;52:155-161. doi: 10.1007/s00262-002-0360-9.

[50] Thanendrarajan S, Nowak M, Abken H, Schmidt-Wolf IG. Combining cytokine-induced killer cells with vaccination in cancer immunotherapy: more than one plus one? Leuk Res 2011;35:1136-1142. doi: 10.1016/ j.leukres.2011.05.005.

[51] Niu LZ, Li JL, Zeng JY, Mu F, Liao MT, Yao F, et al. Combination treatment with comprehensive cryoablation and immunotherapy in metastatic hepatocellular cancer. World J Gastroenterol 2013;19:3473-3480. doi: 10.1097/ MPA.0b013e3182965dde.

[52] Mu F, Niu LZ, Li HB, Liao MQ, Li L, Liu Cy, et al. Percutaneous comprehensive cryoablation for metastatic hepatocellular cancer. Cryobiology 2013;66:7680. doi: 10.1016/j.cryobiol.2012.11.008.

[53] Niu LZ, Li JL, Zeng JY, Mu F, Liao MT, Yao F, et al. Combination treatment with comprehensive cryoablation and immunotherapy in metastatic hepatocellular cancer. World J Gastroenterol 2013;19:3473-3480.

[54] Pearson AS, Izzo F, Fleming RY, Ellis LM, Delrio P, Roh MS, et al. Intraoperative radiofrequency ablation or cryoablation for hepatic malignancies. Am J Surg 1999;178:592-599.

[55] Xu KC, Niu LZ, He WB, Hu YZ, Zuo JS. Percutaneous cryosurgery for the treatment of hepatic colorectal metastases. World J Gastroenterol 2008;14: 1430-1436.

[56] Yang Y, Wang C, Lu Y, Bai W, An L, Qu J, et al. Outcomes of ultrasound-guided percutaneous argon-helium cryoablation of hepatocellular carcinoma. J Hepatobiliary Pancreat Sci 2012;19:674-684. doi: 10.1007/s00534-0110490-6.

[57] Shafir M, Shapiro R, Sung M, Warner R, Sicular A, Klipfel A. Cryoablation of unresectable malignant liver tumors. Am J Surg 1996;171:27-31.

[58] Wong WS, Patel SC, Cruz FS, Gala KV, Turner AF. Cryosurgery as a treatment for advanced stage hepatocellular carcinoma: results, complications, and alcohol ablation. Cancer 1998;82:1268-1278. doi: 10.1002/(SICI)10970142(19980401)82:7<1268: :AID-CNCR9>3.0.CO;2-B
[59] Sandomirsky M, Crifasi JA, Long C, Mitchell EK. Case report of fatal complication in prostatic cryotherapy. First reported death due to argon gas emboli. Am J Forensic Med Pathol 2012;33:68-72. doi: 10.1097/ PAF.0b013e3181dd5b8c.

[60] Hamad GG, Neifeld JP. Biochemical, hematologic, and immunologic alterations following hepatic cryotherapy. Semin Surg Oncol 1998;14:122-128. doi: 10.1002/(SICI)1098-2388(199803)14:2<122: :AID-SSU5>3.0.CO;27.

[61] Kollmar O, Richter S, Czyborra J, Menger MD, Dietrich S, Schilling MK, et al. Aprotinin inhibits local platelet trapping and improves tissue destruction in hepatic cryosurgery. Surgery 2004;136:624-632. doi: 10.1016/ j.surg.2004.02.004.

[62] Pistorius GA, Alexander C, Krisch CM, Feifel G, Schilling MK, Menger MD. Local platelet trapping as the cause of thrombocytopenia after hepatic cryotherapy. World J Surg 2005;29:657-660; discussion 661. doi: 10.1007/ s00268-005-7543-4

[63] Hui P, Cook DJ, Lim W, Fraser GA, Arnold DM. The frequency and clinical significance of thrombocytopenia complicating critical illness: a systematic review. Chest 2011;139:271-278. doi: 10.1378/chest.10-2243.

[64] Nydam TL, Kashuk JL, Moore EE, Johnson JL, Burlew CC, Biffl WL, et al. Refractory postinjury thrombocytopenia is associated with multiple organ failure and adverse outcomes. J Trauma 2011;70:401-406; discussion 406407. doi: 10.1097/TA.0b013e31820b5c85

[65] Olmez I, Zafar M, Shahid M, Amarillo S, Mansfield R. Analysis of significant decrease in platelet count and thrombocytopenia, graded according to NCICTC, as prognostic risk markers for mortality and morbidity. J Pediatr Hematol Oncol 2011;33:585-588. doi: 10.1097/MPH.0b013e318234622f.

[66] Cozzi PJ, Stewart GJ, Morris DL. Thrombocytopenia after hepatic cryotherapy for colorectal metastases: correlates with hepatocellular injury. World J Surg 1994;18:774-776; discussion 777. doi: 10.1007/BF00298929

[67] Sarantou T, Bilchik A, Ramming KP. Complications of hepatic cryosurgery. Semin Surg Oncol 1998;14:156-162. doi: 10.1002/(SICI)10982388(199803)14:2<156::AID-SSU7>3.0.CO;2-4.

[68] Shi J, Niu L, Huang Z, Mu F, Chen J, Li J, et al. Diagnosis and treatment of coagulopathy following percutaneous cryoablation of liver tumors: experience in 372 patients. Cryobiology 2013;67:146-150. doi: 10.1016/j.cryobiol.2013.06.004.

[69] Long XA, Zeng JY, Niu LZ, Yao F, Wang XH, Chen JB, et al. Alleviating the pain of unresectable hepatic tumors by percutaneous cryoablation: Experience in 73 patients. Cryobiology 2013;67:369-373. doi: 10.1016/j.cryobiol.2013.10.005.

[70] Wang CP, Wang H, Qu JH, Lu YY, Bai WL, Dong Z, et al. Tumour seeding after percutaneous cryoablation for hepatocellular carcinoma. World J Gastroenterol 2012;18:6587-6596.

[71] Conners D, Rilling W. Pleural tumor seeding following percutaneous cryoablation of hepatocellular carcinoma. Semin Intervent Radiol 2011;28: 258-260. doi: 10.1055/s-0031-1280677. 